\title{
Pelvic floor muscle function in a general female population in relation with age and parity and the relation between voluntary and involuntary contractions of the pelvic floor musculature
}

\author{
Marijke C. Ph. Slieker-ten Hove • Annelies L. Pool-Goudzwaard • \\ Marinus J. C. Eijkemans • Regine P. M. Steegers-Theunissen • Curt W. Burger • \\ Mark E. Vierhout
}

Received: 19 March 2009 / Accepted: 27 July 2009 /Published online: 4 September 2009

(C) The Author(s) 2009. This article is published with open access at Springerlink.com

\begin{abstract}
Introduction and hypothesis The objective of this study is to describe pelvic floor muscle function (PFMF) in relation to age and parity in a general female population and to test whether strength/endurance measurements represent all functions of the pelvic floor musculature.

Methods A cross-sectional study was performed on $95 \%$ of the women aged 45-85 years from a small Dutch town. Validated questionnaires were used to obtain general information, and vaginal examination to test PFMF was performed on 649 women. Chi-square tests were used to
\end{abstract}

M. C. Ph. Slieker-ten Hove • R. P. M. Steegers-Theunissen •

C. W. Burger

Department of Obstetrics and Gynaecology, Erasmus MC,

University Medical Centre,

Rotterdam, The Netherlands

M. C. Ph. Slieker-ten Hove

Cobra Research Institute,

Amersfoort, The Netherlands

\section{A. L. Pool-Goudzwaard}

Department of Neuroscience, Erasmus MC,

University Medical Centre,

Rotterdam, The Netherlands

M. J. C. Eijkemans

Department of Public Health, Erasmus MC,

University Medical Centre,

Rotterdam, The Netherlands

R. P. M. Steegers-Theunissen

Department of Epidemiology,

Erasmus MC, University Medical Centre,

Rotterdam, The Netherlands analyse the relation between PFMF versus age and parity. Analysis of variance was used to compare muscle strength and endurance to the other PFMF items.

Results Response rate to the questionnaire was $62.7 \%$ $(1,869 / 2,979)$. PFM strength and endurance are not positively associated with the effective involuntary muscle contractions during coughing.

Conclusions Voluntary muscle contractions decreased with age, but there was no relation with parity. Muscle strength and endurance measurements alone are not sensitive enough to determine PFMF.

R. P. M. Steegers-Theunissen

Department Pediatrics/Pediatric Cardiology, Erasmus MC,

University Medical Centre,

Rotterdam, The Netherlands

R. P. M. Steegers-Theunissen

Department Clinical Genetics, Erasmus MC,

University Medical Centre,

Rotterdam, The Netherlands

M. E. Vierhout

Department of Obstetrics and Gynaecology,

Radboud University Nijmegen Medical Centre,

Nijmegen, The Netherlands

M. C. Ph. Slieker-ten Hove $(\bowtie)$

Softwareweg 5,

3821 BN Amersfoort, The Netherlands

e-mail: m.slieker@somt.nl 
Keywords Female · Function · Pelvic floor musculature . Prevalence $\cdot$ Involuntary muscle contraction

\section{Introduction}

The pelvic floor musculature (PFM) is a muscular layer that supports the pelvic organs. PFM function (PFMF) depends on the anatomical position of the muscles, the resting tone, and on the integrity of the fascia. When there is an increase in intra-abdominal pressure (IAP), e.g., during coughing, the PFM must contract (involuntarily) to maintain the support of the pelvic organs. Voluntary contraction of the PFM results in the inward movement of the perineum and upward movement of the pelvic organs. The urethra, anus, and vagina also close [1]. Normal PFMF plays an important role in maintaining urinary or faecal continence and can function as a defence mechanism against sexual intercourse [2].

After voluntary and involuntary contractions of the PFM, complete relaxation must result in the termination of urethral, vaginal, and anal closure. Although it is complicated to test basic PFM tone, studies have been performed using, e.g., a dynamometer [3], but this technique is still at the laboratory model stage. PFM tone scores obtained during manual testing were unreliable. It is difficult to evaluate and compare PFMF, because there are many different methods and scales. Over the past 20 years, three pelvic floor muscle assessments have been used most commonly: the Laycock PERFECT scale with a six-point scale to score muscle strength and endurance, the number of repetitions, and fast contractions; the Brink score to assess muscle strength, urethral lift, and muscle endurance, all with four-point scales; and the Devreese assessment scale, with more PFMF items, including cocontraction of the transverse abdominal muscles [4-6]. However, many items are still missing from all these assessment methods.

The Pelvic Floor Clinical Assessment Group of the International Continence Society (ICS) 2005 has standardised the terminology relevant to pelvic floor muscle functioning [7]. In 2008, this terminology was tested for face validity and reliability [8].

Recently, Talasz et al. [9] used the ICS terminology to study PFMF [7] in geriatric women with urinary incontinence. They demonstrated that more than $87 \%$ of the patients were not aware of the location of the pelvic floor and were unable to perform any voluntary or involuntary contractions of the PFM. It was presumed that these women had never learned to use their PFM in early life and that this had led to PFM dysfunction and urinary incontinence as they became older. In a second study, Talasz et al. tested PFMF in a random group of Austrian women who were visiting a gynaecological outpatient clinic because of non-pelvic floor disorders [10]. Unfortunately, PFM strength was tested with the Oxford grading system that differs from the ICS terminology, in which muscle strength is defined as absent, weak, normal, or strong. Furthermore, inter-tester reliability did not form part of their assessment.

The first treatment option for many pelvic floor disorders is PFM training. However, pelvic floor physiotherapists lack relevant information about PFMF in relation to age and parity in a general population. In current clinical practise, the PFM are generally only tested for strength and endurance, but it is not yet clear whether these two functions cover total PFMF as proposed by the ICS terminology. Therefore, we performed a cross-sectional study to obtain normative data on PFMF in relation to age and parity from a general female population aged 45 85 years. In addition, we analysed whether muscle strength and endurance affected voluntary and involuntary PFM contractions.

\section{Materials and methods}

A cross-sectional study was performed on a general population of mostly white women aged 45 to 85 years, living in the Netherlands. A more detailed description of the study is already published [11]. The total population of women aged $45-85$ years $(n=2,979$ out of 16,000 citizens) registered on the patients lists of eight out of the nine general practises in the town of Brielle (near Rotterdam, the Netherlands) were approached to participate in the present study. All the women were asked to complete a self-report questionnaire. Non-responders received a reminder 8 weeks later after the first contact that contained the same questionnaire. Data were collected anonymously.

\section{Vaginal examination}

Eight hundred women were randomly selected for PFMF assessment. All signed an informed consent. Table 1 presents the PFM assessment scale; the criteria and verbal instructions conform to ICS terminology [7]. Data were obtained by means of visual inspection and palpation of voluntary muscle contraction (VMC) and effective involuntary muscle contraction (IMC) during coughing (that should prevent the perineum from moving in the caudal direction) and muscle relaxation during straining. One gynaecologist and one physiotherapist performed the vaginal examinations. Attention was paid to extensive 
Table 1 Pelvic floor musculature assessment (with verbal instructions between parenthesis)

\begin{tabular}{|c|c|c|}
\hline Visual inspection & Outcome & Outcome measures \\
\hline \multirow[t]{2}{*}{ Co-contraction visible } & Yes & Any co-activity of muscles other than $\operatorname{Tr} A b$ \\
\hline & No & No co-activity of other muscles visible \\
\hline $\begin{array}{l}\text { Palpation during voluntary muscle contraction ('lift and squeeze your PFM' and } \\
\text { if this was not helpful enough, 'try to avoid loss of urine or flatus') }\end{array}$ & & Abbreviation: VMC \\
\hline \multirow[t]{2}{*}{ Urethral lift } & Yes & Any urethral lift palpable \\
\hline & No & No urethral lift palpable \\
\hline \multirow[t]{3}{*}{ Inward movement perineum } & Yes & Any inward movement of the perineum \\
\hline & No & No inward movement of the perineum \\
\hline & Downward & Any downward movement of the perineum \\
\hline \multirow[t]{2}{*}{ Levator closure } & Yes & Any levator closure movement palpable \\
\hline & No & No levator closure movement palpable \\
\hline \multirow[t]{3}{*}{ Voluntary relaxation } & Good & Direct relaxation to rest level \\
\hline & Delayed & Delayed relaxation to rest level \\
\hline & Incomplete & Incomplete relaxation palpable \\
\hline \multirow[t]{4}{*}{$\begin{array}{l}\text { Maximum voluntary contraction ('lift and squeeze your PFM as hard as } \\
\text { possible') }\end{array}$} & Strong & $\begin{array}{l}\text { Strong closure and lifting, cranio-anterior } \\
\text { movement palpable }\end{array}$ \\
\hline & Normal & $\begin{array}{l}\text { Cosure and lifting, cranio-anterior movement } \\
\text { palpable }\end{array}$ \\
\hline & Weak & Short contraction, no closure palpable \\
\hline & Absent & No contraction \\
\hline $\begin{array}{l}\text { Endurance ('make a steady but firm contraction and hold it as long as you can, } \\
\text { while repeating hold and hold and hold') }\end{array}$ & 1 till 10 & \\
\hline $\begin{array}{l}\text { Palpation during involuntary muscle contraction during coughing ('cough } \\
\text { forcefully') }\end{array}$ & & Abbreviation: IMC \\
\hline \multirow[t]{2}{*}{ Movement perineum } & Yes & $\begin{array}{l}\text { No or ineffective contraction that allows any } \\
\text { downward movement of the perineum }\end{array}$ \\
\hline & No & $\begin{array}{l}\text { Effective IMC (no downward movement of the } \\
\text { perineum) }\end{array}$ \\
\hline $\begin{array}{l}\text { Palpation during involuntary muscle relaxation during straining ('give a strong } \\
\text { push') }\end{array}$ & & Abbreviation: IMR \\
\hline \multirow[t]{2}{*}{ Involuntary relaxation } & Yes & Any caudal movement of the perineum \\
\hline & No & No downward movement \\
\hline
\end{tabular}

training of the two examiners before starting the study to $100 \%$ agreement, since each of the examiners was testing half of the women.

\section{Statistical analysis}

Chi-square tests and tests for trend were used to compare individual PFM items with yes/no answers or threecategory scores between four 10-year age categories and four parity categories $(0,1,2$, and $\geq 3)$. Analysis of variance was used to compare the PFM items, VMC, and endurance (scored on a quantitative scale) to the characteristics. Analyses were performed using the Statistical Package for Social Science (SPSS Inc.) 15.0. The Medical Ethics Research Committee of the Erasmus MC, Rotterdam approved this study.

\section{Results}

Response rate

The response rate to the questionnaire was $62.7 \%(1,869 /$ $2,979)$. In the group of 1,869 responders, $472(25.2 \%)$ women refused to participate, 1,397 (74.8\%) women (group 1 in Fig. 1) agreed to fill out the large questionnaire, and $1,140(60.9 \%)$ agreed to fill out the questionnaire and undergo vaginal examination. In group 2, 800 out of the 1,140 women were selected at random and sent an invitation to undergo vaginal examination: 649 women complied $(81.1 \%)$. Thus, $46 \%$ of the total study group underwent vaginal examination $(649 / 1,397)$. In the nonresponder group (group 3), 59\% completed and returned the short questionnaire $(620 / 1,051)$. 
Fig. 1 Flowchart of the study

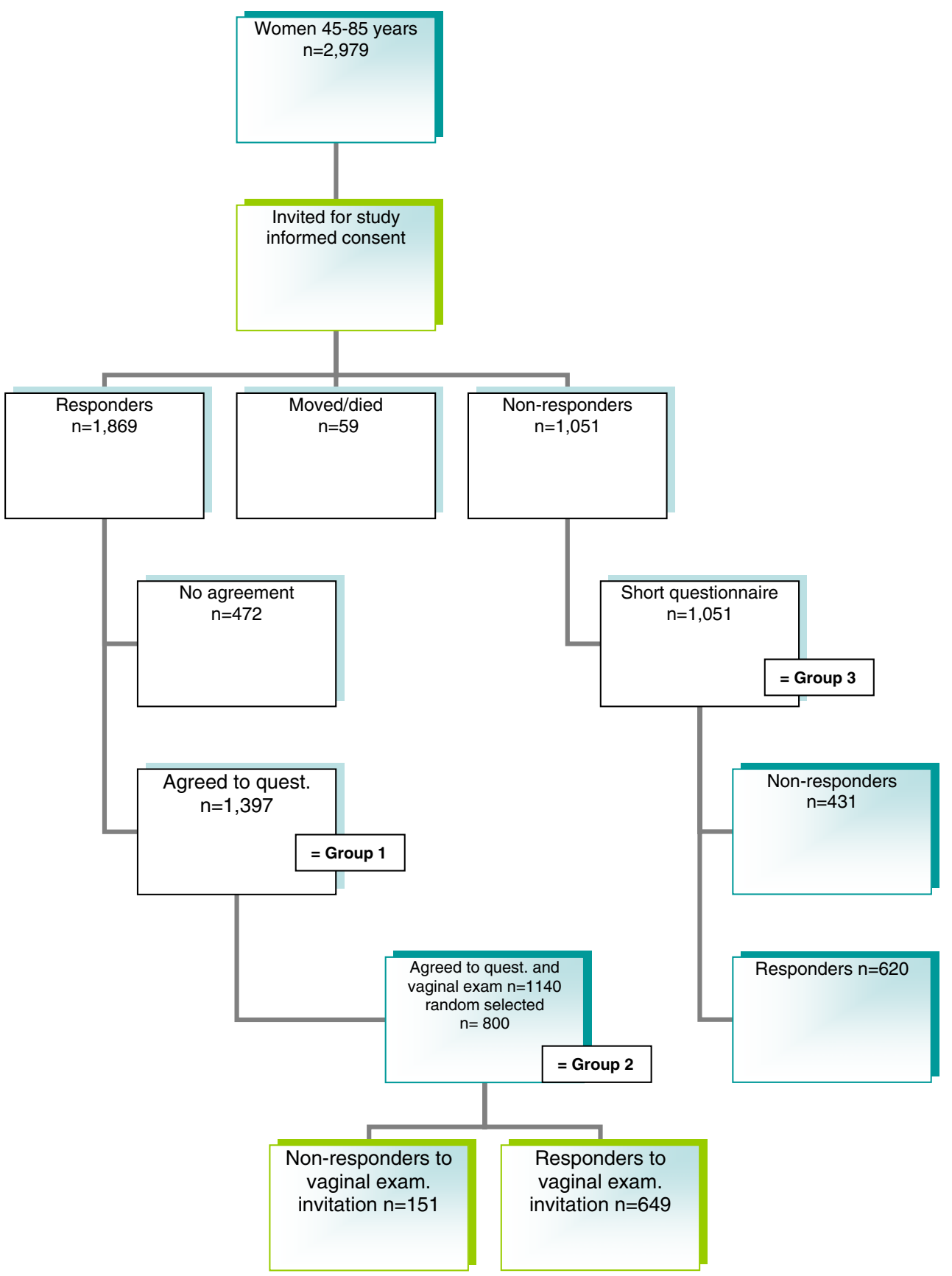

Demographic characteristics

For detailed description of the demographic characteristics of the total study population, we refer to a previous publication [11]. No significant differences were found between responders and non-responders. Table 2 presents the overall results of PFMF obtained from this general population. Although visual inspection showed that only $8.6 \%$ were incontinent during coughing, palpation indicated that $48.4 \%$ were able to perform effective IMC during coughing. In Table 2, PFMF results are also presented in relation to age, analysed with the Chi-square test and test for trend. Decreases in most of the PFMF were found with increasing age, e.g., visible co-contractions, urethral lift, levator closure, inward movement of the perineum, muscle endurance, IMC, and involuntary muscle relaxation. Table 3 presents PFMF in relation to parity. No significant differences were observed between the nulliparous women and the parous women. A trend was seen in levator closure $(p<.1)$. 
Table 2 Pelvic floor muscle function (PFM) in women versus age in 10-year age groups expressed in percentages (individual PFM items with yes/no scores or three category scores)

\begin{tabular}{|c|c|c|c|c|c|c|c|}
\hline & & $\begin{array}{l}\text { Overall } \\
(n=649)\end{array}$ & $\begin{array}{l}45-55 \\
(n=292)\end{array}$ & $\begin{array}{l}56-65 \\
(n=217)\end{array}$ & $\begin{array}{l}66-75 \\
(n=100)\end{array}$ & $\begin{array}{l}76-85 \\
(n=39)\end{array}$ & $p$ value \\
\hline \multicolumn{8}{|l|}{ Visual inspection } \\
\hline \multirow[t]{2}{*}{ Co-contraction visible } & Yes & 34.6 & 28 & 34.6 & 39 & 71.8 & $<.001$ \\
\hline & No & 65.4 & 72 & 65.4 & 61 & 28.2 & \\
\hline \multicolumn{8}{|c|}{ Palpation during voluntary muscle contraction } \\
\hline \multirow[t]{2}{*}{ Urethral lift } & Yes & 62.4 & 70.8 & 58.1 & 61.2 & 28.2 & $<.001$ \\
\hline & No & 37.6 & 29.2 & 41.9 & 38.8 & 71.8 & \\
\hline \multirow[t]{3}{*}{ Inward movement perineum } & Yes & 77.0 & 82.2 & 75.3 & 74.7 & 48.7 & $<.001$ \\
\hline & No & 22.5 & 17.4 & 23.3 & 25.3 & 48.7 & \\
\hline & Downward & 0.8 & 0.3 & 1.4 & 0 & 2.6 & \\
\hline \multirow[t]{2}{*}{ Levator closure } & Yes & 61.9 & 69.6 & 58.8 & 61.6 & 21.6 & $<.001$ \\
\hline & No & 38.1 & 30.4 & 41.2 & 38.4 & 78.4 & \\
\hline \multirow[t]{3}{*}{ Voluntary relaxation } & Good & 51.3 & 56.1 & 45.8 & 51.1 & 47.4 & .111 \\
\hline & Delayed & 28.5 & 26.6 & 31.5 & 27.2 & 28.9 & \\
\hline & Incomplete & 20.2 & 17.3 & 22.7 & 21.7 & 23.7 & \\
\hline \multirow[t]{4}{*}{ Voluntary contraction } & Absent & 5.2 & 5.1 & 5.5 & 5 & 5.1 & $<.001$ \\
\hline & Weak & 31.6 & 21.2 & 37.3 & 41 & 53.8 & \\
\hline & Normal & 58.2 & 66.4 & 53.9 & 50 & 41 & \\
\hline & Strong & 4.9 & 7.2 & 3.2 & 4 & 0 & \\
\hline Endurance mean in seconds & $0-10 \mathrm{~s}$ & 6.24 & 6.83 & 5.93 & 5.84 & 4.56 & $<.001$ \\
\hline \multicolumn{8}{|c|}{ Palpation during involuntary muscle contraction during coughing } \\
\hline Downward movement perineum & Yes (ineff. IMC) & 51.5 & 61 & 46.3 & 34 & 53.8 & $<.001$ \\
\hline No downward movement perineum & No (eff. IMC) & 48.5 & 39 & 53.7 & 66 & 46.2 & \\
\hline \multicolumn{8}{|c|}{ Palpation during involuntary muscle relaxation during straining } \\
\hline Caudal perineal movement & Yes & 89.9 & 93 & 90.3 & 84.7 & 76.9 & $<.001$ \\
\hline No caudal perineal movement & No & 10.2 & 7 & 9.7 & 15.3 & 23 & \\
\hline
\end{tabular}

Muscle strength and endurance versus PFMF

Table 4 shows the results of the analysis of variance on PFM strength and endurance in relation to the other PFMF items. All the items demonstrated significant associations, except for effective IMC during coughing: fewer women with normal or strong PFM were able to perform adequate IMC to resist a sudden increase in IAP during coughing $(41.6 \%$ and $40.6 \%)$ than the women with absent or weak PFM $(52.9 \%$ and $61.5 \%$ ). Women with strong PFM showed less cocontraction, better urethral lift and levator closure, better relaxation, and involuntary muscle relaxation during straining (that resulted in downward movement of the perineum).

\section{Discussion}

We wanted to describe PFMF in relation to age and parity in a general female population and to test whether strength/ endurance measurements reflect all functions of the PFM.
PFMF overall and in relation to age

Sixty-three percent of the women had normal or strong PFM during VMC and were able to achieve urethral lift and levator closure (Table 2). However, only half of the women $(51.3 \%)$ were able to relax voluntarily after VMC, which indicates that the other half of the women were unable to relax properly. This is in contrast with the IMC.

Only half of the women (48.5\%) performed an effective PFM contraction during coughing, while almost all women $(90 \%)$ were able to relax involuntary during straining. The reason is unclear. We hypothesize that postural functions of the PFM can play a role in voluntary contractions and delayed relaxation $[12,13]$. However, this does not explain why half of the women have an ineffective involuntary contraction. The overall results cannot be compared to other studies, since other studies did not use ICS terminology or did not assess a general population.

Significant relations were found between PFMF and age. All items had decreasing scores with increasing age. 
Table 3 Pelvic floor muscle function (PFMF) versus parity in percentages (individual PFM items with yes/no scores or three category scores), ten were missing data on parity in the questionnaire

\begin{tabular}{|c|c|c|c|c|c|c|c|}
\hline & & $0(n=49)$ & $1(n=86)$ & $2(n=321)$ & $\geq 3(n=183)$ & Total $(n)$ & $p$ value \\
\hline \multicolumn{8}{|l|}{ Visual inspection } \\
\hline \multirow[t]{2}{*}{ Co-contraction visible } & Yes & 33.1 & 33.7 & 35.8 & 33.3 & $34.6(220)$ & .973 \\
\hline & No & 66.7 & 66.3 & 64.2 & 66.7 & $65.4(415)$ & \\
\hline \multicolumn{8}{|l|}{ Palpation during voluntary muscle contraction } \\
\hline \multirow[t]{2}{*}{ Urethral lift } & Yes & 73.5 & 63.9 & 61.2 & 62.1 & $62.8(388)$ & .227 \\
\hline & No & 26.5 & 36.1 & 38.8 & 37.9 & $37.2(230)$ & \\
\hline \multirow[t]{3}{*}{ Inward movement perineum } & Yes & 79.6 & 77.1 & 76.4 & 77.2 & $77(482)$ & .936 \\
\hline & No & 18.4 & 21.7 & 22.6 & 22.8 & $22.2(139)$ & \\
\hline & Downward & 2 & 1.2 & 1 & 0 & $0.8(5)$ & \\
\hline \multirow[t]{2}{*}{ Levator closure } & Yes & 73.5 & 63.9 & 61.2 & 62.1 & $62.1(384)$ & .062 \\
\hline & No & 13 & 34.9 & 38.6 & 41.1 & $37.9(234)$ & \\
\hline \multirow[t]{3}{*}{ Voluntary relaxation } & Good & 51.1 & 56.1 & 49.5 & 53.6 & $51.7(307)$ & .783 \\
\hline & Delayed & 29.8 & 23.2 & 29 & 29.2 & $28.3(168)$ & \\
\hline & Incomplete & 19.1 & 20.7 & 21.5 & 17.3 & $20(119)$ & \\
\hline \multirow[t]{4}{*}{ Voluntary contraction } & Absent & 2 & 8.1 & 5.3 & 4.9 & $5.3(34)$ & .427 \\
\hline & Weak & 20.4 & 30.2 & 32.2 & 32.8 & $31.2(199)$ & \\
\hline & Normal & 73.5 & 59.3 & 56.6 & 57.4 & $58.5(373)$ & \\
\hline & Strong & 4.1 & 2.3 & 5.9 & 4.9 & $5(32)$ & \\
\hline Endurance & $0-10 \mathrm{~s}$ & 6.26 & 7.31 & 6.07 & 6.10 & $6.37(3.23)$ & .103 \\
\hline \multicolumn{8}{|c|}{ Palpation during involuntary muscle contraction during coughing } \\
\hline Downward movement perineum & Yes (ineff. IMC) & 51 & 50 & 52.6 & 51.9 & $52(332)$ & .815 \\
\hline No downward movement perineum & No (eff. IMC) & 49 & 50 & 47.4 & 48.1 & $48(307)$ & \\
\hline \multicolumn{8}{|c|}{ Palpation during involuntary muscle relaxation during straining } \\
\hline Caudal perineal movement during straining & Yes & 89.6 & 89.4 & 90.2 & 91.1 & $90.3(568)$ & .647 \\
\hline No caudal movement & No & 10.4 & 10.6 & 9.8 & 8.9 & $9.7(61)$ & \\
\hline
\end{tabular}

Only for voluntary relaxation, this was not significant. These findings can be attributed to the normal process of ageing: muscle mass starts to decrease in the fifth decade and decreases drastically after the age of 60 years [14]. Our results were also in line with other studies on PFM [15-17].

Parity

Surprisingly, no significant differences in PFMF were found between the nulliparous women and any of the parous groups (Table 3). Not even muscle strength was significantly related, while muscle endurance only demonstrated a trend.

Muscle strength and endurance versus other PFMF items

Our second objective was to test whether the assessment of PFM strength and endurance alone represent all functions of the PFMF (Table 4). Indeed, a stronger PFM was significantly related to a proper PFMF as was a weak or absent PFM related to a non-proper PFMF. However, this was only the case during VMC. An opposite significant observation was done during IMC, for in women scoring absent (52.9\%) or weak (61.5\%) PFM strength, an effective PFMF was present: in these women, no downward movement of the perineum occurred during coughing. This was the opposite in women with stronger PFM. This demonstrates that PFM strength and endurance do not represent all functions of the PFM since strength does not represent an effective IMC during coughing. We hypothesize that this can be due to the fact that the PFMF are in principle under both voluntary and involuntary control (reflex) [18-20]. It might be that during reflexes, motor units of the PFM will be activated which will not be active during voluntary contraction. Our finding was in contrast with the results reported by Talasz et al., who demonstrated a relation between muscle strength and IMC. However, this can be explained by the different scoring methods: in the study by Talasz et al., the presence of pre-contraction was scored, but not whether this IMC was effective, and prevented the perineum from moving in the caudal direction during an increase in IAP when coughing. In addition, the mean age in the study by Talasz et al. was 
Table 4 Pelvic floor muscle strength and endurance versus all other tested pelvic floor muscle function items in percentages

\begin{tabular}{|c|c|c|c|c|c|c|c|c|c|}
\hline \multirow[t]{2}{*}{ PFM function } & & \multicolumn{5}{|c|}{ PFM strength (Chi-square) } & \multicolumn{3}{|c|}{ Endurance (ANOVA) } \\
\hline & & $\begin{array}{l}\text { Absent } \\
(n=34)\end{array}$ & $\begin{array}{l}\text { Weak } \\
(n=205)\end{array}$ & $\begin{array}{l}\text { Normal } \\
(n=377)\end{array}$ & $\begin{array}{l}\text { Strong } \\
(n=33)\end{array}$ & $p$ value & Mean & SD & $p$ value \\
\hline \multicolumn{10}{|l|}{ Visual inspection } \\
\hline \multirow[t]{2}{*}{ Co-contraction visible } & Yes & 60.6 & 46.3 & 28.1 & 9.4 & $<.001$ & 4.74 & 3.33 & $<.001$ \\
\hline & No & 39.4 & 53.7 & 71.9 & 90.6 & & 7.04 & 2.96 & \\
\hline \multicolumn{10}{|c|}{ Palpation during voluntary muscle contraction } \\
\hline \multirow[t]{2}{*}{ Urethral lift } & Yes & 2.9 & 23.8 & 85.1 & 96.6 & $<.001$ & 7.90 & 2.31 & $<.001$ \\
\hline & No & 97.1 & 76.2 & 14.9 & 3.1 & & 3.47 & 2.78 & \\
\hline \multirow[t]{3}{*}{ Inward movement perineum } & Yes & 5.9 & 49.5 & 96.5 & 93.5 & $<.001$ & 7.37 & 2.58 & $<.001$ \\
\hline & No & 91.2 & 48.5 & 3.5 & 6.5 & & 2.63 & 2.65 & \\
\hline & Downward & 2.9 & 2.0 & 0 & 0 & & 1.80 & 1.10 & \\
\hline \multirow[t]{2}{*}{ Levator closure } & Yes & 0 & 31.6 & 80.4 & 96.6 & $<.001$ & 7.83 & 2.35 & $<.001$ \\
\hline & No & 100 & 68.4 & 19.6 & 3.1 & & 3.69 & 2.94 & \\
\hline \multirow[t]{3}{*}{ Voluntary relaxation } & Good & 10.3 & 30.1 & 62.4 & 87.5 & $<.001$ & 7.42 & 2.94 & $<.001$ \\
\hline & Delayed & 3.4 & 37.1 & 27.8 & 9.4 & & 6.16 & 2.67 & \\
\hline & Incomplete & 86.2 & 323.8 & 9.8 & 3.1 & & 6.31 & 3.28 & \\
\hline \multirow[t]{4}{*}{ Voluntary contraction } & Absent & & & & & & 0.24 & 1.05 & \\
\hline & Weak & & & & & & 3.88 & 2.58 & \\
\hline & Normal & & & & & & 7.87 & 2.21 & \\
\hline & Strong & & & & & & 8.72 & 2.28 & $<.001$ \\
\hline Endurance mean (SD) & $0-10 \mathrm{~s}$ & 0.23 & 3.88 & 7.87 & 8.72 & $<.001$ & & & \\
\hline \multicolumn{10}{|c|}{ Palpation during involuntary muscle contraction during coughing } \\
\hline Downward movement perineum & Yes (ineff. IMC) & 47.1 & 38.5 & 58.4 & 59.4 & $<.001$ & 6.57 & 3.42 & $<.001$ \\
\hline No downward movement perineum & No (eff. IMC) & 52.9 & 61.5 & 41.6 & 40.6 & $<.001$ & & & \\
\hline \multicolumn{10}{|c|}{ Palpation during involuntary muscle relaxation during straining } \\
\hline Caudal perineal movement & Yes & 67.6 & 84.0 & 94.9 & 90.6 & $<.001$ & & & \\
\hline No caudal movement perineum & No & 32.4 & 16.0 & 5.1 & 9.4 & & 6.51 & 3.17 & $<.001$ \\
\hline
\end{tabular}

much younger (41.2/18-79 years versus 56/45-85 years) and was not performed in a general population [10].

According to our clinical experience the past 10 years, only VMCs have been used to test awareness of the PFM, muscle strength, muscle endurance, timing, and urethral lift $[4,5]$. In our opinion, several items are missing, especially levator closure, IMC during coughing, and involuntary relaxation during straining.

It is of even more concern that a study by Davis and Kumar demonstrated that PFMF assessment is often neglected during gynaecological consultations visit [21].

Strengths and limitations of the study

One of the strengths of our study was the ethnic homogeneity, because almost all of the women were white, which eliminated racial bias from the results. Furthermore, broad data were obtained from a large general study group using a combination of questionnaires and vaginal examination.

Although this study was performed on a general female population, the mean body mass index of 25 and the $98 \%$ white race mean that caution must be taken if the results are extrapolated to other general populations.

A limitation can be a possible bias in the women who volunteered in participating in the vaginal examination. However, from the 1,397 women that filled in the questionnaire, $81.6 \%(1,140 / 1,397)$ were willing to participate in the examination.

Another limitation can be the reliability of the assessment scale. Since only a reasonable intra-rater reliability was scored, we did not enlarge the number of examiners. Nevertheless, by training the examiners to $100 \%$ agreement prior to the research, we expect to have increased the reliability. Of course, the assessment tool needs further study to develop a tool that can be used in science by every researcher. 
Although face validity of the assessment scale has been tested, no construct validity research has been performed. We recommend further research into the development of this assessment tool. It is important to test validity of the assessment scale in the near future and to make adaptations to achieve higher intra- and inter-rater observer reliability.

The assessment did not include the existence of the contraction before coughing. Because this was not easy to measure without equipment, we focussed on the effectiveness of the contraction regarding the movement of the perineum.

\section{Conclusions}

We obtained data on the prevalence of a wide range of PFMF items from a general female population. PFMF differed significantly between the age groups and decreased with increasing age. These findings were in contrast with parity, in which no significant differences were observed. Muscle strength and endurance were related to a proper voluntary PFMF while not related to the ability to achieve effective IMC. Therefore, the implication for clinicians is that voluntary and IMC should be included in PFM assessment to be able to establish whether PFMF is involved in the patient's presenting symptoms.

Acknowledgements We are very grateful to the women who participated in this study and to Mrs. G. M. Schoenmaker MD and her group of general practitioners for their hospitality and cooperation in this study.

Funding Unrestricted grant from NV Organon, Oss, The Netherlands.

Conflicts of interest None.

Open Access This article is distributed under the terms of the Creative Commons Attribution Noncommercial License which permits any noncommercial use, distribution, and reproduction in any medium, provided the original author(s) and source are credited.

\section{References}

1. DeLancey JO (1997) The pathophysiology of stress urinary incontinence in women and its implication for surgical treatment. World J Urol 15(5):268-274

2. Van Der Velde J, Laan E, Everaerd W (2001) Vaginismus, a component of a general defensive reaction. An investigation of pelvic floor muscle activity during exposure to emotion-inducing film excerpts in women with and without vaginismus. Int Urogynecol J Pelvic Floor Dysfunct 12:328-331

3. Dumoulin C, Gravel D, Bourbonnais D, Lemieux MC, Morin M (2004) Reliability of dynamometric measurements of the pelvic floor musculature. Neurourol Urodyn 23(2):134-142
4. Laycock J (1991) Incontinence. Pelvic floor re-education. Nursing (Lond) 4:15-17

5. Brink CA, Sampselle CM, Wells TJ, Diokno AC, Gl G (1989) A digital test for pelvic muscle strength in older women with urinary incontinence. Nurs Res 38:196-199

6. Devreese A, Staes F, De Weerdt W et al (2004) Clinical evaluation of pelvic floor muscle function in continent and incontinent women. Neurourol Urodyn 23:190-197

7. Messelink B, Benson T, Berghmans B, Bø K, Corcos J, Fowler C, Laycock J, Lim PH, van Lunsen R, Lycklama a Nijeholt $G$, Pemberton J, Wang A, Watier A, Van Kerrebroeck P (2005) Standardisation of terminology of pelvic floor muscle function and dysfunction: report from the pelvic floor clinical assessment group of the international continence society. Neurourol Urodyn 24:374-380

8. Slieker-Ten Hove MC, Pool-Goudzwaard AL, Eijkemans MJ, Steegers-Theunissen RP, Burger CW, Vierhout ME (2009) Face validity and reliability of the first digital assessment scheme of pelvic floor muscle function conform the new standardized terminology of the International Continence Society. Neurourol Urodyn 28(4):295-300

9. Talasz H, Gosch M, Enzelsberger H, Rhomberg HP (2005) Geriatrische Patientinnen mit Harninkontinenz-Symptomen und ihre Kontrolle über den Beckenboden. Z Gerontol Geriatr 38:424430

10. Talasz H, Himmer-Perschak G, Marth E, Fischer-Colbrie J, Hoefner E, Lechleitner M (2008) Evaluation of pelvic floor muscle function in a random group of adult women in Austria. Int Urogynecol J Pelvic Floor Dysfunct 19(1):131-135

11. Slieker-ten Hove MC, Pool-Goudzwaard AL, Eijkemans MJ, Steegers-Theunissen RP, Burger CW, Vierhout ME (2009) Symptomatic pelvic organ prolapse and possible risk factors in a general population. Am J Obstet Gynecol 200(2):184.e1184.e7

12. Hodges PW, Sapsford R, Pengel LH (2007) Postural and respiratory functions of the pelvic floor muscles. Neurourol Urodyn 26(3):362-371

13. Pool-Goudzwaard A, van Dijke GH, van Gurp M, Mulder P, Snijders C, Stoeckart R (2004) Contribution of pelvic floor muscles to stiffness of the pelvic ring. Clin Biomech (Bristol) 19 (6):564-571

14. Deschenes MR (2004) Effects of aging on muscle fibre type and size. Sports Med 34(12):809-824

15. Chen L, Ashton-Miller JA, Hsu Y, DeLancey JO (2006) Interaction among apical support, levator ani impairment, and anterior vaginal wall prolapse. Obstet Gynecol 108(2):324332

16. Trowbridge ER, Wei JT, Fenner DE, Ashton-Miller JA, Delancey JO (2007) Effects of aging on lower urinary tract and pelvic floor function in nulliparous women. Obstet Gynecol 109(3):715-720

17. Perucchini D, DeLancey JO, Ashton-Miller JA, Galecki A, Schaer GN (2002) Age effects on urethral striated muscle. II. Anatomic location of muscle loss. Am J Obstet Gynecol 186:356

18. Deindl FM, Vodusek DB, Hesse U, Schussler B (1993) Activity patterns of pubococcygeal muscles in nulliparous continent women. Br J Urol 72(1):46-51

19. Blok BF, van Maarseveen JT, Holstege G (1998) Electrical stimulation of the sacral dorsal gray commissure evokes relaxation of the external urethral sphincter in the cat. Neurosci Lett 249:68-70

20. Vereecken RL, Derluyn J, Verduyn H (1975) Electromyography of the perineal striated muscles during cystometry. Urol Int 30:92-98

21. Davis K, Kumar D (2003) Pelvic floor dysfunction: a conceptual framework for collaborative patient-centred care. J Adv Nurs 43 (6):555-568 